Revue d'histoire de l'Amérique française

Q4. REVUE D'HISTOIRE DE L'AMÉRIQUE FRANÇAISE

\title{
Une note de voyage - Une allocution
}

\section{Olivier Maurault}

Volume 1, numéro 1, juin 1947

URI : https://id.erudit.org/iderudit/801347ar

DOI : https://doi.org/10.7202/801347ar

Aller au sommaire du numéro

Éditeur(s)

Institut d'histoire de l'Amérique française

ISSN

0035-2357 (imprimé)

1492-1383 (numérique)

Découvrir la revue

Citer ce document

Maurault, O. (1947). Une note de voyage - Une allocution. Revue d'histoire de l'Amérique française, 1(1), 91-93. https://doi.org/10.7202/801347ar d'utilisation que vous pouvez consulter en ligne.

https://apropos.erudit.org/fr/usagers/politique-dutilisation/ 


\section{UNE NOTE DE VOYAGE - UNE ALLOCUTION ${ }^{1}$}

\section{Cavelier de La Salle au Texas}

Notre séjour au Texas avait surtout pour but de rechercher les traces de Cavelièr de La Salle. C'est là qu'il erra, de 1684 à 1687, en quête du Mississipi. Nous retrouvâmes son tragique souvenir à Navasota et sur les bords de la rivière Garcitas.

La rivière Garcitas coule dans la baie de Matagorda, une de ces baies ou lagunes disséminées tout le long de la côte du golfe du Mexique. Cavelier de La Salle avait d'abord dressé son camp face au golfe, puis, pour plus de sûreté, l'avait fixé à l'intérieur sur une côte assez élevée, d'où la vue commandait une plaine fertile. Le camp Saint-Louis s'y déploya avec ses ouvrages de défense, sa chapelle, ses habitations. Après le départ de Cavelier de La Salle, un montréaliste, du nom de Barbier, en fut le commandant. On sait que tout cela fut détruit par les Indiens et que, sauf deux enfants, tous les colons furent massacrés. Plus tard, les Espagnols construisirent, au même lieu, un fort qui fut détruit à son tour. Des archéologues du pays sont parvenus à préciser l'endroit de ces deux établissements et l'Etat projette d'y aménager un parc du souvenir et un monument commémoratif.

C'est au bord d'une autre rivière, le rio Brazos, que Cavelier de La Salle devait rencontrer la mort. Beaucoup plus au nord, entre Houston et Austin, la petite ville de Navasota garde pieusement le souvenir de ce tragique assassinat. Sur sa place publique, elle a élevé un monument de bronze au célèbre découvreur. Au pied de son socle, il y eut échange de politesses et de discours; on nous remit une médaille, on nous fleurit de blue-bonnets, la fleur du Texas, et nous lajssâmes des autographes dans des albums de jeunes écolières. En sortant de cet humble bourg, nous retraversâmes le rio Brazos, encore bien loin

1. Mgr Olivier Maurault, empêché de faire davantage, a voulu quand même faire acte de présence dans la première livraison de la Revue. Il nous envoie ces pages. 
de son embouchure. C'est là que Cavelier de La Salle, accompagné de son frère l'abbé Jean, prêtre de Saint-Sulpice, d'un Père Récollet et de quelques hommes, s'était un soir arrêté. Il connaissait cette région, habitée par les Indiens Cenis. Son neveu, Moranger, ayant eu une querelle avec quelques compagnons, au sujet d'une misérable affaire de nourriture, il voulut aller voir ce qui s'était passé. En l'apercevant, le nommé Duhaut l'aîné le tua à bout portant, le dépouilla et le jeta dans un hallier. Ses cendres y sont restées.

Que de fois en sillonnant ce Texas illimité, fleuri de cactus et de blue-bonnets, en franchissant ces rivières nombreuses qu'il avait nommées, nous avons songé à Cavelier de La Salle, s'en allant, vêtu d'un costume de pourpre et d'or, à la recherche de son fleuve fantôme...

\section{UN DOCTORAT ${ }^{1}$}

\section{Messieurs,}

Nous voulons honorer aujourd'hui une brillante vocation d'historien qui, sitôt affirmée, fut favorisée par la famille, orientée et maintenue par elle. Cet exemple trop rare de logique et de continuité nous est donné par la Société de Jésus, la famille dont je viens de parler. Ce fut, tout le long de son histoire, une de ses caractéristiques de se connaître en hommes, de savoir les former et de les placer ensuite au poste qui leur convient. Dès les premières années de son ministère sacerdotal, ses maîtres décelèrent les qualités d'historien du R. P. Delanglez; ils lui ouvrirent la voie et ils l'ont laissê la parcourir, se contentant de lui suggérer quelques itinéraires. C'est ainsi qu'il est devenu l'historien des Religieux de son Ordre en Louisiane.

Sa première thèse l'avait conduit dans une toute autre direction. Après ses études de théologie à Dublin, il était allé préparer un doctorat en histoire à l'université de Munich et portait son attention sur " l'ambassade de Possuen à la cour d'Ivan le Terrible ". Ce fut pour lui l'occasion d'apprendre l'allemand et le russe.

1. Allocution prononcée, à l'Université de Montréal, le 23 avril 1947, après le dernier cours du P. Delanglez, professeur invité et membre-correspondant de I' « Institut d'Histoire de l'Amérique française "). 
Il fut alors rappelé en Amérique pour écrire l'histoire des Jésuites de la Louisiane. Ce travail lui mérita un doctorat d'histoire de l'Université catholique de Washington.

Mais les Jésuites ont été partout en Amérique. Ils y ont rencontré Jolliet et Robert Cavelier de la Salle, et son frère Jean et LaMothe Cadillac et tant d'autres. Le P. Delanglez a étudié leur œuvre à tous; il l'a fait avec la méthode précise et sans peur qu'il a lui-même exposée dans un livre.

Car, mon Révérend Père, si vous êtes devenu Etatsunien par élection et avec une entière franchise, vous avez conservé les qualités fondamentales de votre race d'origine. Belge de naissance, Américain par votre carrière, vous avez uni la clarté d'esprit et la formation classique du vieux pays à la liberté et à la hardiesse du jeune continent. Et cette alliance a fait de vous un historien de premier ordre, dont la méthode impeccable et les jugements courageux sont une leçon bienfaisante. Vous êtes tout le contraire d'un amateur bien doué ou d'un heureux improvisateur; vous êtes un maître au métier sûr et à l'érudition étendue.

L'institution qui vous compte parmi ses professeurs, doit être fière de vous avoir à son service; votre réputation rejaillit sur elle et lui attire des étudiants. Vous avez eu comme élève, à l'Université de Chicago, un de nos jeunes maîtres les mieux écoutés. Vous étiez par là, déjà un peu de notre maison; nous voulons que dorénavant vous en soyez tout à fait.

C'est pourquoi l'Université de Montréal est heureuse de vous décerner, ce soir, un doctorat ès-lettres " honoris causa ".

Mgr Olivier Maurault, p.s.s., Recteur de l'Université de Montréal. 